\title{
Fulminant Hepatitis Due to Father-to-Newborn Transmission of Herpes Simplex Virus type 1
}

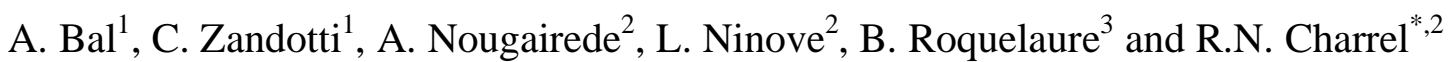 \\ ${ }^{I}$ IHU Mediterranee Infection, APHM Public Hospitals of Marseille, 13005 Marseille, France \\ ${ }^{2}$ UMR_D 190 "Emergence des Pathologies Virales", Aix Marseille Univ, IRD French Institute of Research for \\ Development, EHESP French School of Public Health, 13005, Marseille, France \\ ${ }^{3}$ Unité de médecine infantile et de pneumologie pédiatrique, APHM-Timone-enfants, 264, rue Saint-Pierre, 13385 \\ Marseille cedex 05, France
}

\begin{abstract}
We describe a case of a severe neonatal infection by herpes simplex virus (HSV) type 1 acquired postnatally from his father. The delivery and the first days of life were normal. He developed liver failure and disseminated intravascular coagulation when he was 19 days old. He was treated with intravenous acyclovir and the outcome was favorable. This case underlines that prevention of post-natal transmission of HSV merits to be considered in educational pregnancy programs directed at mothers and fathers.
\end{abstract}

Keywords: E. coli, HSV1, infection, transmission.

\section{INTRODUCTION}

Human herpes simplex virus (HSV) causes lifelong infections, a vast majority of which do not manifest clinically. Neonatal HSV infection can be acquired in utero (transplacental hematogenic transmission), at delivery (the most frequent route via direct contact of the baby with infected vaginal secretions) or postnatally (indirect transmission), and cause significant morbidity and mortality $[1,2]$. HSV infections in newborns are classified into three patterns, occurring with equal frequency, disseminated disease involving multiple visceral organs, central nervous system disease, and disease limited to the skin, eyes, and mouth [3]. Postnatally acquired HSV infections are rarely reported and the source of infection remains poorly documented. We report here one case for which extensive investigations were conducted to document it to the best of our possibilities.

\section{CASE REPORT}

A 8-day old male newborn was admitted to the emergency ward for abdominal pain with $39^{\circ} \mathrm{C}$ fever. Escherichia coli pyelonephritis was laboratory-documented on the urine sample. At this time, except for an elevated inflammatory marker (CRP $=15 \mathrm{mg} / 1)$, liver function tests, blood cell count and hemostasis markers were normal. He was transferred to pediatric unit to receive intravenous antibiotics. Eleven days later, his condition suddenly deteriorated with jaundice, abdominal collateral circulation, hepatosplenomegaly, and diarrhea in a febrile context

*Address correspondence to this author at the UMR_D 190 "Emergence des Pathologies Virales", Faculty of Medicine, 27 blvd Jean Moulin 13005, Marseille, France; Tel: +33491324420; Fax: +33491324421;

E-mail: remi.charrel@univ-amu.fr $\left(39.5^{\circ} \mathrm{C}\right)$ suggesting splenic hypertension; he was transferred to the neonatal intensive care unit. Biologic analyses showed a severe hepatic failure (prothrombin ratio at 25\%, fibrinogen at $0.19 \mathrm{~g} / \mathrm{L}$ ) with severe cytolytic hepatitis (AST = 2,720 IU/L, ALT = 1,353 IU/L, normal range = 6-40 IU/L), moderate cholestasis (total bilirubin at $119 \mu \mathrm{mol} / \mathrm{L}$ ), severe thrombocytopenia $(13 \mathrm{~g} / \mathrm{L})$ and disseminated intravascular coagulation (fibrin monomer at $50 \mu \mathrm{g} / \mathrm{mL}$, activated coagulation time at $58 \mathrm{sec}$ ). He was transfused with platelet, plasma and fibrinogen units. An empirical treatment by aciclovir was started. Bacterial sepsis was ruled out since blood and CSF cultures were negative. Other conditions such as metabolic disease, macrophage activation syndrome and hemochromatosis were negative (myelogram, iron status). Hepatotropic viruses (hepatitis A-E viruses, Cytomegalovirus, Herpes simplex virus (HSV), varicellazoster virus, and Epstein-Barr virus) were tested via serology and PCR or RT-PCR-based genome amplification, but were negative except for HSV for which acute serum contained IgM, and HSV PCR was positive in whole blood and in the liver biopsy [4]. HSV type 1 (HSV-1) infection was confirmed using PCR based typing [5]. Histologic analysis of the liver biopsy showed a severe disseminated cytolysis. Thorough clinical examination of the patient did not find either mucocutaneous vesicles or encephalitis signs. Before this episode and apart from the pyelonephritis, the first 3 weeks of life were associated with normal weight gain. The treatment by intravenously acyclovir was prolonged during 21 days. The clinical and biological examinations progressively improved and the newborn was discharged after one month.

\section{DISCUSSION}

Mother-to-newborn transmission at the delivery time is unlikely due to the following facts and regarding the related 
data in the literature: (i) There was an absence of genital lesions [6]. (ii) The serological profile of the mother (HSV IgG-positive / HSV IgM-negative / HSV real-time PCR negative) indicated a past immunity against HSV and the absence of reactivation. (iii) The newborn developed normally with normal weight gain in the first 3 weeks of life. (iv) The hepatitis signs and symptoms were developed 11 days post admission, i.e. 19 days after birth. The long delay between birth and HSV-1 signs is strong evidence against the per-delivery infection due to active virus shedding in an asymptomatic mother (v) The post natal transmission is almost always due to HSV-1 [7].

Assuming post-natal transmission of HSV-1, the fatherto-infant transmission is much more likely than the motherto-infant transmission because upon interview (i) the father reported a lesion highly suggestive of oro-labial herpes when the newborn was first hospitalized, (ii) he recalled and spontaneously reported to have repeatedly kissed his son while he was symptomatic, (iii) he declared that he often presented recurring oro-labial herpes lesions.

The $E$. coli infection seems to be an intercurrent infection that has played no role other that provoking the hospitalization. Although there is no undisputable evidence, according to the aforementioned array of data, the HSV-1 infection of the newborn is much more likely to have been acquired from his father than from his mother.

In Light's comprehensive review of postnatal acquired HSV infection in newborn infants (less than 28 day-old), there is no report of father-to-infant transmission between 1959 and 1977 [8]. A thorough bibliographic search retrieved only two cases where father-to-newborn transmission was reported $[9,10]$. In our case, the issue was excellent; however it is likely that the 3-week acyclovir treatment has played a major role in the favorable outcome.

Because, the etiological quest of severe sepsis in newborn is difficult and that delayed therapy jeopardizes the outcome, it is recommended to start empiric acyclovir treatment when cytolytic hepatitis is diagnosed $[8,11]$. In addition, the risks and means of prevention of post-natal transmission of HSV should be considered in educational programs associated with pregnancy.

\section{AUTHORS CONTRIBUTION}

Laboratory tests: Zandotti C, Ninove L.

Data collection: Bal A, Zandotti C, Ninove L, Roquelaure

B.

Article writing and revisions: Bal A, Charrel RN.

Supervision: Zandotti C, Charrel RN.

\section{CONFLICT OF INTEREST}

The authors declare that they have no conflict of interest.

\section{ACKNOWLEDGEMENTS}

Declared none.

\section{REFERENCES}

[1] Kimberlin DW. Neonatal herpes simplex infection. Clin Microbiol Rev 2004; 17(1): 1-13.

[2] Brown ZA, Wald A, Morrow RM, Selke S, Zeh J, Corey L. Effect of serologic status and cesarean delivery on transmission rates of herpes simplex virus from mother to infant. JAMA 2003; 289: 203-9.

[3] Kimberlin DW, Lin CY, Jacobs RF, et al. Natural history of neonatal herpes simplex virus infections in the acyclovir era. Pediatrics 2001; 108(2): 223-9.

[4] Kessler HH, Mühlbauer G, Rinner B, et al. Detection of Herpes Simplex Virus DNA by Real-Time PCR. J Clin Microbiol 2000; 38: $2638-42$.

[5] Weidmann M, Meyer-Köning U, Hufert FT. Rapide detection of Herpes simplex virus and varicella zoster virus infections by RT PCR. J Clin Microbiol 2003; 41: 1565-68.

[6] O'Riordan DP, Golden WC, Aucott SW. Herpes simplex virus infections in preterm infants. Pediatrics 2006; 118: e1612-20.

[7] Kimberlin DW. Herpes simplex virus infections in neonates and early childhood. Semin Pediatr Infect Dis 2005; 16: 271-81.

[8] Light IJ. Postnatal acquisition of herpes simplex virus by the newborn infant:a review of the literature. Pediatrics 1979; 63: 4802.

[9] Van der Wiel H, Weiland HT, van Doornum GJ, van der Straaten PJ, Berger HM. Disseminated neonatal herpes simplex virus infection acquired from the father. Eur J Pediatr 1985; 144: 56-7.

[10] Yeager AS, Ashley RL, Corey L. Transmission of herpes simplex virus from father to neonate. J Pediatr 1983; 103: 905-7.

[11] Fidler KJ, Pierce CM, Cubitt WD, Novelli V, Peters MJ. Could neonatal disseminated herpes simplex virus infections be treated earlier? J Infect 2004; 49: 141-6. 